Original Research Article

\title{
Evaluation of compound tibial fractures managed with an Ilizarov ring fixator
}

\section{Praveen Ravi*, Muthumanickam Ramanujam, Jambu Nageswaran, Sundar Suriyakumar}

\begin{abstract}
Department of Orthopaedics, Sri Ramachandra Institute of Higher Education and Research, Porur, Chennai, Tamil
\end{abstract} Nadu, India

Received: 21 January 2020

Revised: 28 April 2020

Accepted: 29 April 2020

\author{
*Correspondence: \\ Dr. Praveen Ravi, \\ E-mail: praveenravi2010@gmail.com
}

Copyright: (c) the author(s), publisher and licensee Medip Academy. This is an open-access article distributed under the terms of the Creative Commons Attribution Non-Commercial License, which permits unrestricted non-commercial use, distribution, and reproduction in any medium, provided the original work is properly cited.

\begin{abstract}
Background: The tibia is the most commonly fractured long bone and because of its location and the tenuous soft tissue coverage, its more prone for open fractures tibia than any other long bone. The ideal management of such fractures still remains controversial. We have evaluated the healing of fractures and functional outcomes in patients with open tibial fractures treated with an Ilizarov ring fixator.

Methods: 32 patients who had open fractures of the tibia (II, IIIA or IIIB) who were treated with an Ilizarov fixator were included in the study. The patients were followed up for a minimum period of 1 year after removal of the fixator. Functional and radiological results were analysed using association for the study of applications of methods of Ilizarov scoring.

Results: There were 20 cases of type IIIB, 7 cases of type IIIA, 5 cases of type II fractures. Union was achieved in all patients. Mean time for union was 25.2 weeks, with faster union times in type II, type IIIA fractures. Six cases of type IIIB needed flap cover. Limb discrepancy was seen in 3 cases. 17 cases of pin tract infections were seen, most of which were grade 3 and were managed with antibiotics. Two cases had delayed union, of which one was treated with bone marrow aspirate injection and the other one with bone grafting. At one year, $21(65.6 \%)$ had excellent results, six $(18.7 \%)$ had good results, four $(12.5 \%)$ had fair outcomes and one $(3.2 \%)$ had a poor result.

Conclusions: Despite the associated complications, Ilizarov fixator is the ideal treatment for compound tibial fractures.
\end{abstract}

Keywords: Compound tibial fractures, Ilizarov fixators, Pin tract infections

\section{INTRODUCTION}

The tibia is the most commonly fractured long bone and because of its location and the tenuous soft tissue coverage, its more prone for open fractures tibia than any other long bone. ${ }^{1}$ Open fractures coupled with severe comminution frequently leads to delayed union or nonunion. The ideal management of such fractures still remains controversial. Current concepts of management focuses on thorough debridement and immediate bony stabilisation for restoration of ideal function. ${ }^{2}$ Studies have shown that open fractures treated with conventional half pin fixators followed by plate fixation are associated with high rates of non-union and frequently needing secondary procedures. ${ }^{3}$ Current fixation systems have developed to maintain endosteal circulation in open fractures to avoid the union problems. Unreamed intramedullary nailing and circular external fixator (Ilizarov) have been proven to provide a 'protective fixation' preserving the endosteal circulation. However, both modalities are associated with their own advantages and disadvantages. Intramedullary nailing allows for early mobilisation and weight bearing 
and is less cumbersome as compared to an Ilizarov fixator. However the use of intramedullary implants in open fractures are associated with higher rates of infection and frequently requires secondary surgeries. ${ }^{4}$ Ilizarov fixator is an elastic type of external fixator and allows for axial micro motion at the fracture site which promotes bone regeneration. It is also a multiplanar and multilevel fixator, which, because of its circumferential design allows for more even distribution of stresses at the fracture site. It allows for three-dimensional correction since there is provision for axial compression and distraction, correction of angular and translational displacements through realignment. It provides an ideal environment for bone healing since it resists shear forces at the fracture site. It also causes less damage is done to the surrounding tissues. But however, it is accompanied with few disadvantages like a risk of pin tract infections, low acceptance by patients, bulky apparatus, difficulties in assembly. Moreover, the K-wires are placed across the muscle tissue and are retained for a long period of time. This leads to restriction of motion in the neighbouring joints. ${ }^{5}$

In our study, we have evaluated the healing of fractures and functional outcomes in patients with open tibial fractures treated with an Ilizarov ring fixator.

\section{METHODS}

This was a tertiary care hospital based prospective observational study carried out at Sri Ramachandra Medical College and Research Institute between April 2016 to April 2019. All patients were explained extensively regarding the principles and biomechanics of an Ilizarov fixator and informed consent was obtained. Patients with an open fracture (Gustilo-Anderson types II, IIIA, IIIB) of the tibia, with or without an associated fibula and presenting within 72 hours from the initial injury were included in our study. Polytrauma patients, GustiloAnderson type I and IIIC fractures, patients with associated intra articular fracture extensions, those with head injuries and other conditions that delayed definitive orthopaedic interventions were excluded.

Morphology of the fractures was classified according to the modified Gustilo-Anderson classification (Table 1). ${ }^{6}$ The Gustilo-Anderson classification is the most widely used system and the generally accepted classification system for open fractures. This classification takes into account the energy of trauma causing the fracture, extent of soft tissue damage and the degree of contamination. Types I and II are low energy fractures. Type I fractures are those with a wound size of $1 \mathrm{~cm}$ and that of type II are those with more than $1 \mathrm{~cm}$. This classification system has been modified since the original classification to allow for a more accurate grading of more severe injuries (i.e. type III injuries).

Initial interventions like splinting of the leg, primary care for the wound, resuscitation were carried out in the emergency room. Swabs were taken from the wound and gram staining and cultures were sent for, on arrival. All cases were taken up for emergency debridement and temporary stabilisation under anesthesia. Obvious contaminants over the wound and foreign bodies were removed. The wounds were washed adequately with normal saline ( 6 litres for type II and type IIIA and 10 litres for type IIIB), and thorough debridement of the wound, removing all devitalised tissues were done. The exposed bone was covered, whenever possible by approximating the skin using stay sutures. Protruding bone fragments if any were reduced and covered with the soft tissues or with sterile dressings when a soft tissue closure was not possible. The fractures were stabilised using an uniplanar external fixator consisting of two Schanz pins on either side of the fracture. The fixator was placed spanning the knee and the ankle in fractures involving the proximal third and the distal third respectively. All patients were started on third generation cephalosporins, aminoglycosides and metronidazole until the cultures were reported.

Table 1: Gustillo Anderson classification.

\begin{tabular}{|c|c|c|}
\hline Type & Wound description & Other criteria \\
\hline $\mathbf{I}$ & $\begin{array}{l}<1 \mathrm{~cm} \text { (so-called } \\
\text { puncture wounds) }\end{array}$ & \\
\hline II & $1-10 \mathrm{~cm}$ & \\
\hline IIIA & $\begin{array}{l}>10 \mathrm{~cm} \text {, coverage } \\
\text { available }\end{array}$ & $\begin{array}{l}\text { Segmental fractures, } \\
\text { farm injuries, or any } \\
\text { injury occurring in a } \\
\text { highly contaminated } \\
\text { environment. High- } \\
\text { velocity gunshot } \\
\text { injuries }\end{array}$ \\
\hline IIIB & $\begin{array}{l}10 \mathrm{~cm} \text {, requiring soft } \\
\text { tissue coverage } \\
\text { procedure }\end{array}$ & Periosteal stripping \\
\hline IIIC & & $\begin{array}{l}\text { With vascular injury } \\
\text { requiring repair }\end{array}$ \\
\hline
\end{tabular}

Definitive fixation with an Ilizarov ring fixator was done three to five days following the emergency debridement and stabilisation. Pre-assembled Ilizarov frames were used. $1.8 \mathrm{~mm}$ Ilizarov wires and three or four Ilizarov rings were used for stabilisation and alignment. The Schanz pins used in the initial fixator were also incorporated into the Ilizarov system whenever possible. In cases where there were many loose small bony fragments which had to be removed, bone ends were approximated. This approximation aided in the closure of the wound. However, in cases with a bone loss of $2 \mathrm{~cm}$ or more, approximation was not done. Seven patients had a bone loss of $2 \mathrm{~cm}$ or more and underwent corticotomy to allow for distraction. Wound debridement was done and if the wound was deemed healthy and approximable, closure was done. Delayed primary closure was achieved in ten cases. A split skin graft was sufficient in sixteen cases and six cases needed a flap cover for the wound. The average duration of the procedure was 1 hour and 55 minutes, with more time needed in cases undergoing corticotomy. All patients were given antibiotics for a minimum of 5 days. 
The patients and their attendants were taught about pin tract care and ring care. Knee and ankle mobilisation exercises were started on POD 1. All patients were made to stand with support after 24 hours and partial weight bearing was commenced within 48 hours. Full weight bearing was allowed as per the patients' pain tolerance. Distraction was started on post-operative day 7 at a rate of $0.25 \mathrm{~mm}$ per day. The patients were discharged after they were familiar with distraction methods and pin tract care.

Patients were followed up periodically and assessed for frame stability, pain at the fracture site, varus and valgus malalignment, knee and ankle movements, limb length discrepancies, condition of the wound, pin tracts. Radiological and clinical assessment of union was done. If no callus was appreciable even after 6 weeks, compression at the fracture site was done. Radiological bony union was ascertained when there was periosteal bridging and obliteration of the fracture line by endosteal callus formation. When union appeared to be present the frame was dynamised for three to four weeks, following which it was removed. The final follows up was done one year following removal of the frame or the patellar tendon bearing cast. The results were analysed using association for the study of applications of methods of Ilizarov scoring system (Table 2 and 3). ${ }^{7}$ An excellent bone result was one with adequate union, with no signs of infection, with a deformity of $<7$ and limb length discrepancy of $<2.5 \mathrm{~cm}$. A good result indicated union with any two of the other criteria. A fair result implied union with only one of the other criteria. A poor result was one with either a nonunion or a refracture or union with infection and deformity $>7$ and limb length discrepancy of $>2.5 \mathrm{~cm}$. According to the same score, functional results were graded as excellent if the patient is active, with no limp, minimal knee and knee stiffness (loss of $<15$ of knee extension or $<15$ of ankle dorsiflexion), no reflex sympathetic dystrophy, insignificant pain. A good result was an active patient with one or two of the other parameters. Fair was an active patient with three or all of the other parameters. An inactive patient was graded as a poor result and a patient requiring amputation was graded as failure.

Table 2: ASAMI scoring- bone results.

\begin{tabular}{|ll|}
\hline $\begin{array}{l}\text { ASAMI } \\
\text { scoring }\end{array}$ & Description \\
\hline Excellent & $\begin{array}{l}\text { Union, no infection, deformity }<7, \\
\text { limb length discrepancy }<2.5 \mathrm{~cm}\end{array}$ \\
\hline Good & $\begin{array}{l}\text { Union }+ \text { any two of the following: } \\
\text { absence of infection }<7 \text { deformity } \\
\text { and limb length inequality of }<2.5 \\
\text { cm }\end{array}$ \\
\hline Fair & $\begin{array}{l}\text { Union }+ \text { only one of the following: } \\
\text { absence of infection, deformity }<7 \\
\text { and limb length inequality }<2.5 \mathrm{~cm}\end{array}$ \\
\hline Poor & $\begin{array}{l}\text { Non union/refracture/union }+ \\
\text { infection }+ \text { deformity }>7+\operatorname{limb} \\
\text { length inequality }>2.5 \mathrm{~cm}\end{array}$ \\
\hline
\end{tabular}

Table 3: ASAMI scoring- functional results.

\begin{tabular}{|ll|}
\hline $\begin{array}{l}\text { ASAMI } \\
\text { scoring }\end{array}$ & Description \\
\hline Excellent & $\begin{array}{l}\text { Active, no limp, minimum stiffness } \\
\text { (loss of <15 knee extension/ <15 } \\
\text { dorsiflexion of ankle), no reflex } \\
\text { sympathetic dystrophy (RSD), } \\
\text { insignificant pain }\end{array}$ \\
\hline Good & $\begin{array}{l}\text { Active, with one or two of the } \\
\text { following: limp, stiffness, RSD } \\
\text { significant pain }\end{array}$ \\
\hline Fair & $\begin{array}{l}\text { Active, with three or all of the } \\
\text { following: limp, stiffness, RSD } \\
\text { significant pain }\end{array}$ \\
\hline Poor & $\begin{array}{l}\text { Inactive (unemployment or inability } \\
\text { to perform daily activities because } \\
\text { of injury) }\end{array}$ \\
\hline Failures & Amputation \\
\hline
\end{tabular}

Institutional ethics committee approval was obtained prior to beginning the study. The collected results were analysed with IBS SPSS software 23.0 version. After dividing the data into quantitative and qualitative variables the data was analysed using frequency analysis, percentage analysis, mean, SD, Pearson Chi-square test. Univariate analysis was also carried out.

\section{RESULTS}

34 patients underwent the procedure of whom were 2 were lost for follow up after 3 months. 27 male patients and 5 female patients (male:female 5.4:1) (Figure 1), who underwent the procedure and completed a minimum period of follow up of 18 months were included. The age of the patients ranged from 19 years to 58 years (mean age 35.1 years), with the patients between 20 to 40 years comprising of $78.1 \%$ the cases. The right leg involved in 26 cases $(81 \%)$ and the left leg in 6 patients (19\%) (Figure 2).

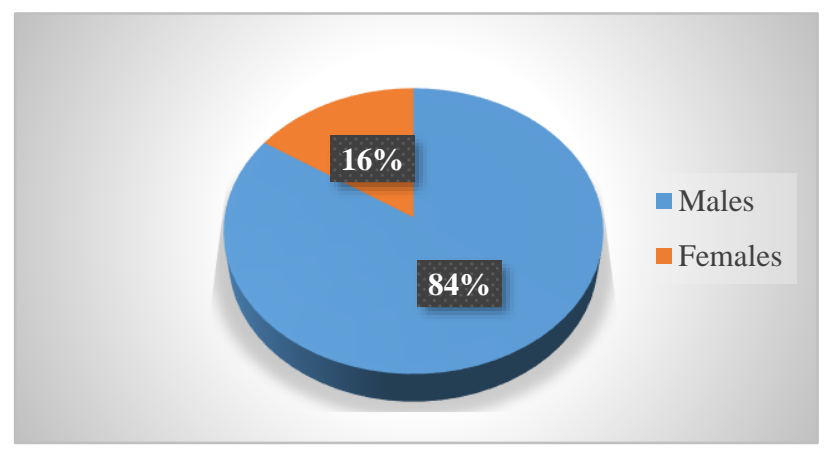

Figure 1: Sex distribution of study population.

The most common mechanism was road traffic accidents comprising upto $87.5 \%$ (28 patients) followed by 3 incidences of fall from height and 1 case of a workplace injury. Twenty-two $(68.7 \%)$ patients presented to our hospital within 24 hours following the injury, seven 
(21.8\%) between 24 hours and 48 hours and three $(9.5 \%)$ patients between 48 to 72 hours. There were ten cases $(31.3 \%)$ involving the proximal third, thirteen $(40.6 \%)$ involving the middle third and nine $(28.1 \%)$ of the distal third of the leg. In our study type IIIB fractures were the most common accounting to 20 patients $(62.5 \%)$, followed by type IIIA with 7 patients $(21.8 \%)$ and five patients with type II fractures $(15.7 \%)$. Defintive fixation was done for seventeen patients $(53.2 \%)$ on the third day, eight patients on the fourth day $(25 \%)$ and seven patients $(21.8)$ on the fifth day. The average duration of hospital stay was 9.2 days ( 7 to 15 days).

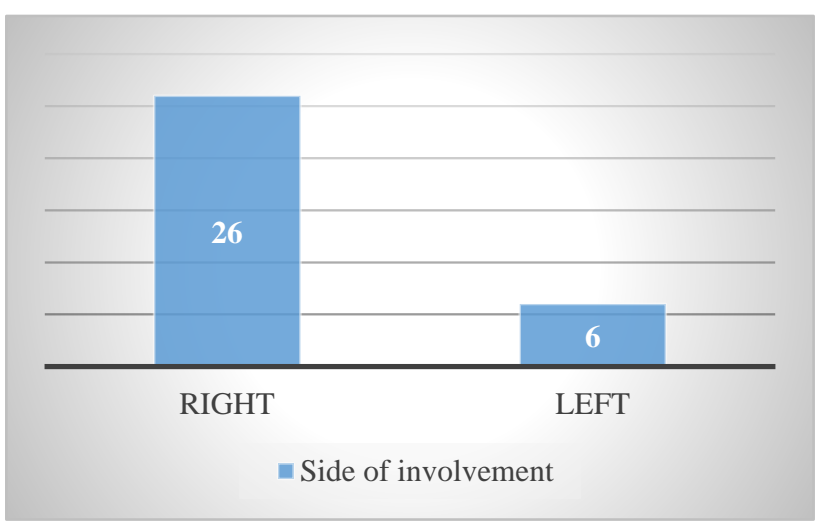

Figure 2: Side of involvement.

Union at the fracture site was achieved in all patients. The earliest evidence of radiological union was observed at 12 weeks following the procedure. Union time was defined as the time when both clinical (absence of pain or movement when walking full weight bearing on the limb) and radiological union (bridging callus seen in two planes) were complete. The mean time for union in cases without a bone loss was 22.9 weeks ranging between 12 weeks to 31 weeks. The mean time in type II fractures was 20.8 weeks (SD-2.49), 22.3 weeks (SD-3.12) in type IIIA fractures and 24.8 weeks (SD-3.48) in type IIIB fractures (without bone loss). There were no statistical differences seen between the three groups $(p>0.05)$. The union time was significantly higher in seven type IIIB cases which had a bone loss and subsequently underwent lengthening. The average time to union was 29.8 weeks (SD-6.16). The average length of the defect was $4.1 \mathrm{~cm}$ ranging from 2.5 $\mathrm{cm}$ to $6 \mathrm{~cm}$. There was statistical difference seen when comparing the union time of all type IIIB fractures (with and without bone loss) against type II and type IIIA fractures $(\mathrm{p}<0.05)$.

All the type II cases and few of the type IIIA, IIIB cases were closed with delayed primary closure. Other four type IIIA and twelve type IIIB cases were managed with a split skin graft. Six cases of type IIIB fractures required a repeat debridement and negative pressure wound therapy before proceeding with a flap cover (Table 4). Limb discrepancy was seen in 3 cases. All such cases were type IIIB cases without a bone loss. The differences were $2.6 \mathrm{~cm}, 2.9 \mathrm{~cm}$ and $3.1 \mathrm{~cm}$ in the cases. They were given a choice for bone transport and lengthening, but they refused. There were 4 cases with a residual angulation at 1 year follow up.

Table 4: Modalities of wound management.

\begin{tabular}{|lllll|}
\hline $\begin{array}{l}\text { Management of } \\
\text { wound }\end{array}$ & $\begin{array}{l}\text { Type } \\
\text { II }\end{array}$ & $\begin{array}{l}\text { Type } \\
\text { IIIA }\end{array}$ & $\begin{array}{l}\text { Type } \\
\text { IIIB }\end{array}$ & Total \\
\hline $\begin{array}{l}\text { Delayed primary } \\
\text { closure }\end{array}$ & 5 & 3 & 2 & 10 \\
\hline Split skin grafting & - & 4 & 12 & 16 \\
\hline $\begin{array}{l}\text { Musculocutaneous } \\
\text { flap cover }\end{array}$ & - & - & 6 & 6 \\
\hline Total & 5 & 7 & 20 & 32 \\
\hline
\end{tabular}

Table 5: List of complications.

\begin{tabular}{|c|c|c|c|c|}
\hline Complications & $\begin{array}{l}\text { Type } \\
\text { II }\end{array}$ & $\begin{array}{l}\text { Type } \\
\text { IIIA }\end{array}$ & $\begin{array}{l}\text { Type } \\
\text { IIIB }\end{array}$ & Total \\
\hline \multicolumn{5}{|l|}{ Pin tract infections } \\
\hline Grade 1 & 1 & 1 & 0 & 2 \\
\hline Grade 2 & - & 3 & 2 & 5 \\
\hline Grade 3 & - & 1 & 6 & 7 \\
\hline Grade 4 & - & - & 3 & 3 \\
\hline Grade 5 & - & - & - & - \\
\hline \multicolumn{5}{|c|}{ Other complications } \\
\hline Knee extensor lag & - & - & 2 & 2 \\
\hline $\begin{array}{l}\text { Restricted ankle } \\
\text { ROM }\end{array}$ & - & 1 & 2 & 3 \\
\hline $\begin{array}{l}\text { Limb length } \\
\text { discrepancy }\end{array}$ & - & - & 3 & 3 \\
\hline $\begin{array}{l}\text { Pain at the fracture } \\
\text { site }\end{array}$ & - & 1 & 3 & 4 \\
\hline RSD & - & 2 & 2 & 4 \\
\hline
\end{tabular}

The complications encountered are listed in Table 5. The most common complication encountered in our series was that of pin tract infections. It was seen in 17 cases (47 pin sites). The infections were graded and treated as per Moore and Dahl classification. Most of the cases had grade 3 infection. Grade 1 infections were managed with frequent pin care with half strength hydrogen peroxide and normal saline. Grade 2 and 3 were managed with antibiotics and monitored pin site care. There were 3 cases with grade 4 wherein the offending pin was removed and the soft tissue was debrided and astringent irrigation was done. No cases of grade 5 infection were encountered in our study. None of the patients had refracture, either with the frame or after removal.

All patients were started on early knee and ankle physiotherapy. However, two patients had an extensor lag of the knee and three had restricted dorsiflexion of the ankle. There was limp present in the 3 patients with a limb length discrepancy. Four patients had symptoms suggestive of reflex sympathetic dystrophy. Four cases had pain at the fracture site which was manageable with occasional analgesics. One case had a poor result and was inactive. There were no cases of failure, requiring amputation. 
Table 6: Functional outcomes at the end of 12 months.

\begin{tabular}{|lllll|}
\hline $\begin{array}{l}\text { Functional } \\
\text { outcome }\end{array}$ & Excellent & Good & Fair & Poor \\
\hline Type II & 5 & - & - & - \\
\hline Type IIIA & 5 & 2 & - & - \\
\hline Type IIIB & 11 & 4 & 4 & 1 \\
\hline Total & 21 & 6 & 4 & 1 \\
\hline
\end{tabular}

Two cases had delayed union, one in the metaphyseal region which was treated with bone marrow aspirate injection and the other one in the diaphysis required bone grafting in the 3rd month. No incidence of non union was seen. On final evaluation after mobilising for a period of one year without supports, $21(65.6 \%)$ had excellent results, six $(18.7 \%)$ had good results, four $(12.5 \%)$ had fair outcomes and one (3.2\%) had a poor result (Table 6).

\section{DISCUSSION}

Open fractures of the tibia are notorious due to inadequate soft tissue cover at the anterior part of the leg and associated tissue loss in high-energy traumas. ${ }^{7,8}$ Degree of wound contamination, amount of soft tissue damage and surgeon expertise are the key determinants in the outcome of such injuries. ${ }^{5}$ Previously, immobilisation and casting was considered as the first line of management in such fractures. However, with the current options available, many surgeons have moved on to fixation with plates and screws, the use of intramedullary nails and external fixators. ${ }^{5,9}$ Prompt evaluation of the open fracture, tissue debridement under sterile conditions, initiation of appropriate antibiotic cover and fixation of fracture are the key dictums which remain unchanged in the management. ${ }^{10,11}$ Plate fixation is associated with a number of complications, especially in comminuted fractures. Allan et al reported osteomyelitis in $19 \%$ of open tibial fractures treated with plate fixation. ${ }^{12}$ In recent years primary intramedullary nailing is gaining wide acceptance for the treatment of open tibial fractures in developed countries. $^{13}$ Nevertheless intramedullary devices are associated with problems of infections and delayed unions. External fixators have become the go-to alternative because of relative ease of the procedure and the limited disruption of the blood supply of the tibia. However, these advantages are potentially outweighed by the high incidence of pin-tract infections, non unions, difficulties relating to soft-tissue management and risk of malunion.
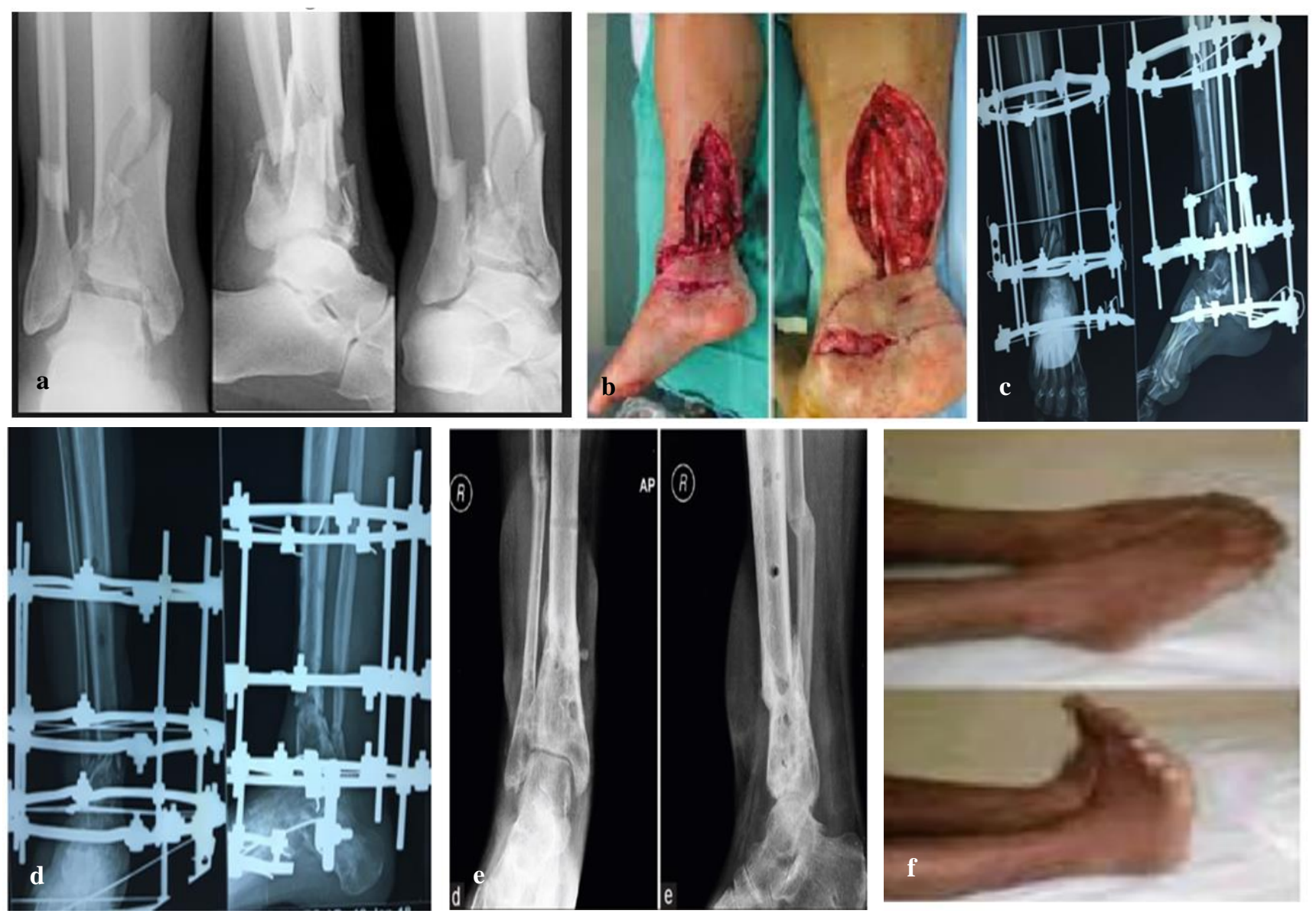

Figure 3: Case illustration of type IIIB both bone leg fracture treated with Ilizraov fixator; (a) the initial $\mathrm{X}$ ray, (b) soft tissue condition, (c) immediate post op following Ilizarov ring application, (d) follow up at 18 weeks showing evidence of union, (e) bony union and alignment after removal of Ilizarov and (f) skin condition and ankle movements after removal. 
Despite the aforementioned risks and complications, Ilizarov ring fixator provides a safe and effective treatment modality for open tibial fractures. Hosny et al showed union in all 34 open tibial fractures managed with Ilizarov. ${ }^{14}$ Sidharthan et al also achieved union in all 42 high energy tibial fractures managed with Ilizarov and advocated its use in high energy tibial fractures, since it provides an early and definitive management of the fractures. ${ }^{15}$ Wani et al have also shown union in all 60 open tibial fractures treated with an Ilizarov ring fixator. ${ }^{16} \mathrm{We}$ have also achieved union in all 32 open tibia fractures treated with an Ilizarov. The results are more appealing due to the fact that there were more cases of type IIIB $(62.5 \%)$ fractures, all of which have united without any incidence of osteomyelitis. This high union rate is attributed mainly to the minimally invasive nature of the fixator thereby requiring minimal stripping of the soft tissues and limiting the subsequent interference with the vascularity of the fracture. Intramedullary nailing on the other hand, interferes with the intramedullary circulation.

The time to union in our study was comparable with the results found by Wani et al. ${ }^{16}$ The union time in type IIIB fractures without associated bone loss was comparable with those in type II or IIIA. However, when fractures with bone loss are also included the difference in union time becomes significant. This may be attributed to the more extensive soft tissue damage in cases with a bone loss.

Wound healing process proceeds for the first five to seven days irrespective of whether the wound is closed. Thus, delayed suturing in wounds within five days achieves the wound strength equal to primary closure. ${ }^{17}$ Since the Ilizarov fixator was applied three to five days after the initial debridement, we were able to achieve wound closure in all type II and a few type IIIA fractures. The number of additional procedures required to achieve wound coverage is thus reduced by the use of an Ilizarov fixator three to five days following the injury.

The number of secondary procedures required with Ilizarov is less compared to other modalities. Wound coverage procedures usually constitute the bulk of secondary procedures in Ilizarov fixation. Other procedures needed are usually related to pin replacement. In contrast, nailing is associated with a risk of non-union, infections and malunion which might warrant additional procedures. Tibial nailing is associated with a significant risk of infection since it impairs the intramedullary circulation. Since, Ilizarov is minimally invasive and does not interfere with the biology of the fracture, it is associated with decreases rates of infection and non union.

Ilizarov fixator allows for early mobilisation by allowing partial to full weight bearing within 48 hours if the pain is within tolerable limits. This causes axial compression at the fracture site which stimulates bone healing. Though it is less stiff in the axial compression, it is moderately to highly stiff in AP and lateral bending strains. The multiplanar orientation of the wires virtually eliminates any late displacement of fragments and thus avoiding malunion. An Ilizarov fixator also enables the surgeon to correct any malalignments arising during the course of treatment.

There are a number of complications associated with Ilizarov but most of these are minor and were seen to be associated more with type IIIB fractures. Pin tract infections form the bulk of complications. ${ }^{18}$ The infections are superficial and mild in most of the cases. However a nidus of infection increases the risk of wire loosening and frame instability due to the weight borne by the fixator. Appropriate care of pin sites and aggressive management of superficial infections is essential to prevent deep infections and septic arthritis (in cases with wires close to the subchondral bone). Insufficient pin care has been associated with higher incidence of pin tract complications. ${ }^{19}$ Muscle contracture and joint stiffness are significant problems, especially seen in patients with the fixator being applied for a prolonged period and in fractures in the proximity of the joints. ${ }^{20}$ Early and vigorous range of motion exercises are crucial in achieving a good functional outcome. Refracture in the consolidate is a troublesome complication, which can be seen in up to $8 \%$ of cases. ${ }^{21}$ The cause for these fractures is usually early removal of the frame. Malunion, which is a frequent complication with nailing, is much less common with Ilizarov since it allows for malalignment correction while the bone is undergoing union or lengthening.

\section{CONCLUSION}

Technical constraints such as pin site infections, restriction of wire placements near the joints are still a problem in the use of this fixator. However, as it allows for early full weight bearing mobilisation, has higher union rates and lesser incidences of malunion, the use of Ilizarov external fixator maintains its importance in the management of open tibial fractures.

\section{ACKNOWLEDGEMENTS}

I express my gratitude to my colleagues and parents for supporting me through the period of this study.

Funding: No funding sources Conflict of interest: None declared

Ethical approval: The study was approved by the institutional ethics committee

\section{REFERENCES}

1. Nicol SA. Closed and open management of tibial fractures. Clin Orthop Relat Res. 1974;105:144-53.

2. Gustilo RB, Markow RL, Templeman D. Current concept review: the management of open fractures. J Bone Joint Surg Am. 1990;72:299-303.

3. Bilat C, Leutenegger A, Ruedi T. Osteosynthesis of 245 tibial fractures, early and late complications. Injury. 1994;25:349-58. 
4. Busse JW, Morton E, Lacchetti C, Guyatt GH, Bhandari M. Current management of tibial shaft fractures: A survey of 450 Canadian orthopedic trauma surgeons. Acta Orthop. 2008;79(5):689-94.

5. Inan M, Tuncel M, Karaoglu S, Halici M. Treatment of type II and III open tibial fractures with Ilizarov external fixation. Acta Orthop Traumatol Turc. 2002;36:390-6.

6. Gustilo RB, Mendoza RM, Williams DN. Problems in the management of type III (severe) open fractures: a new classification of type III open fractures. J Trauma. 1984;24:742-6.

7. Shahid M, Hussain A, Bridgeman P, Bose D. Clinical outcomes of the Ilizarov method after an infected tibial non union. Arch Trauma Res. 2013;2(2):71-5.

8. Brumback RJ. The rationales of interlocking nailing of the femur, tibia, and humerus. Clin Orthop Relat Res. 1996;324:292-320.

9. Chapman MW. The effect of reamed and nonreamed intramedullary nailing on fracture healing. Clin Orthop Relat Res. 1998;(355):230-8.

10. Templeman DC, Gulli B, Tsukayama DT, Gustilo RB. Update on the management of open fractures of the tibial shaft. Clin Orthop Relat Res. 1998;(350):18-25.

11. Olson SA. Open fractures of the tibial shaft. Current treatment. J Bone Joint Surg [Am]. 1996;78:1428-37.

12. Bach AW, Hansen ST Jr. Plates versus external fixation in severe open tibial shaft fractures. A randomized trial. Clin Orthop Relat Res. 1989;241:89-94.

13. Finkemeier CG, Schmidt AH, Kyle RF, Templeman DC. A prospective, randomized study of intramedullary nails inserted with and without reaming for the treatment of open and closed fractures of the tibial shaft. J Orthop Trauma. 2000;14:187-93.
14. Hosny G, Fadel M. Ilizarov external fixator for open fractures of the tibial shaft. Int Orthop. 2003;27(5):303-6.

15. Sidharthan S, Sujith A, Rathod AK, Pathak RH. Management of high energy tibial fractures using the Ilizarov apparatus. Int J Orthop Surg. 2005;2(2).

16. Wani N, Baba A, Kangoo K. Role of early Ilizarov ring fixator in the definitive management of type II, IIIA and IIIB open tibial shaft fractures. Int Orthop (SICOT). 2011;35:915-23.

17. Olson SA, Finkemeier CG, Moehring HD. Open fractures. In: Bucholz RW, Heckman JD, eds. Rockwood and Green's fractures in adults, 5th edn. Lippincott Williams \& Wilkins; 2001: 285-318.

18. Cierny G, Byrd HS, Jones RE. Primary versus delayed soft tissue coverage for severe open tibial shaft fractures. Clin Orthop. 1983;178:54-63.

19. Thayur RM, Balasundaram R, Manjunath KS. Outcomes of Ilizarov ring fixation in recalcitrant infected tibial non-unions - a prospective study. J Trauma Manag Outcomes. 2008;2:6.

20. Inan M, Halici M, Ayan I, Tuncel M, Karaoglu S. Treatment of type IIIA open fractures of tibial shaft with Ilizarov external fixator versus unreamed tibial nailing. Arch Orthop Trauma Surg. 2007;127(8):61723.

21. Inan M, Tuncel M, Karaoğlu S, Halici M. Treatment of type II and III open tibial fractures with Ilizarov external fixation. Acta Orthop Traumatol Turc. 2002;36(5):390-6.

Cite this article as: Ravi P, Ramanujam M, Nageswaran J, Suriyakumar S. Evaluation of compound tibial fractures managed with an Ilizarov ring fixator. Int J Res Orthop 2020;6:710-6. 